\title{
Site-Specific Risk Factors for Ray Blight in Tasmanian Pyrethrum Fields
}

Sarah J. Pethybridge, Botanical Resources Australia - Agricultural Services Pty. Ltd., Ulverstone, Tasmania, 7315, Australia; David H. Gent, United States Department of Agriculture - Agricultural Research Services (USDA-ARS), Forage Seed and Cereal Research Unit and Oregon State University, Department of Botany and Plant Pathology, Corvallis, OR 97331; Paul D. Esker, University of Wisconsin, Department of Plant Pathology, Madison, WI 53706; William W. Turechek, USDA-ARS, U.S. Horticultural Research Laboratory, Subtropical Plant Pathology Unit, Fort Pierce, FL 34945; Frank S. Hay, Tasmanian Institute of Agricultural Research, University of Tasmania, Burnie, Tasmania, 7320, Australia; and Forrest W. Nutter, Jr., Department of Plant Pathology, Iowa State University, Ames, IA 50011

\begin{abstract}
Pethybridge, S. J., Gent, D. H., Esker, P. D., Turechek, W. W., Hay, F. S., and Nutter, F. W., Jr. 2009. Site-specific risk factors for ray blight in Tasmanian pyrethrum fields. Plant Dis. 93:229237.

Ray blight of pyrethrum (Tanacetum cinerariifolium), caused by Phoma ligulicola var. inoxydablis, can cause defoliation and reductions of crop growth and pyrethrin yield. Logistic regression was used to model relationships among edaphic factors and interpolated weather variables associated with severe disease outbreaks (i.e., defoliation severity $\geq 40 \%$ ). A model for September defoliation severity included a variable for the product of number of days with rain of at least $0.1 \mathrm{~mm}$ and a moving average of maximum temperatures in the last 14 days, which correctly classified (accuracy) the disease severity class for $64.8 \%$ of data sets. The percentage of data sets where disease severity was correctly classified as at least $40 \%$ defoliation severity (sensitivity) or below $40 \%$ defoliation severity (specificity) were 55.8 and $71 \%$, respectively. A model for October defoliation severity included the number of days with at least $1 \mathrm{~mm}$ of rain in the past 14 days, stem height in September, and the product of the number of days with at least $10 \mathrm{~mm}$ of rain in the last 30 days and September defoliation severity. Accuracy, sensitivity, and specificity were $72.6,73.6$, and $71.4 \%$, respectively. Youden's index identified predictive thresholds of 0.25 and 0.57 for the September and October models, respectively. When economic considerations of the costs of false positive and false negative decisions and disease prevalence were integrated into receiver operating characteristic (ROC) curves for the October model, the optimal predictive threshold to minimize average management costs was 0 for values of disease prevalence greater than 0.2 due to the high cost of false negative predictions. ROC curve analysis indicated that management of the disease should be routine when disease prevalence is greater than 0.2 . The models developed in this research are the first steps toward identifying and weighting site and weather disease risk variables to develop a decision-support aid for the management of ray blight of pyrethrum.
\end{abstract}

Pyrethrum (Tanacetum cinerariifolium) is a perennial plant in the family Asteraceae that is cultivated for the production of six closely related esters called pyrethrins, which possess insecticidal properties $(7,10,48)$. Pyrethrum is an integral component of the cropping system rotation used in the northwest coast of Tasmania, contributing approximately $30 \%$ of the world's supply of pyrethrins. The crop is planted by seed from July to September, and harvests are conducted annually for the duration of the crop (typically 4 to 5 years) (34).

In the absence of fungicide applications in spring, ray blight, a fungal disease caused

Corresponding author: S. J. Pethybridge E-mail: Sarah.Pethybridge@gmail.com

Accepted for publication 2 November 2008.

doi:10.1094/PDIS-93-3-0229

(C) 2009 The American Phytopathological Society by Phoma ligulicola var. inoxydablis, can reduce plant growth and pyrethrin yield in Tasmania $(31,34,36,40)$. Ray blight was first observed causing minor losses on pyrethrum flowers in Tasmania in 1995 (41). Since 1999, considerable losses have been reported in Tasmania from foliar dieback on developing stems in early spring caused by a severe form of ray blight $(33,37)$. A disease causing similar symptoms, also known as "ray blight," occurs on garden chrysanthemum (Chrysanthemum morifolium) $(2,3,4,11)$. Disease on both hosts causes necrotic lesions on leaves that lead to defoliation, less branching and stunting of stems, and necrotic lesions resulting in girdling, necrotic stem tips, and twisted, distorted, and stunted stems that fail to elongate $(4,37,40)$. Together, these symptoms cause a reduction in green leaf area, thereby reducing radiation interception which reduces yield potential. In severe outbreaks or if management strategies are not applied, plant death and the early termination of the crop $(31,32,37,38,40)$.
Current management tactics for ray blight in pyrethrum rely on the use of at least two to three applications of fungicides, the first of which is applied when stems emerge from semi-dormancy in early spring (generally July to August) $(38,40)$. Fungicides included in the current management recommendations are from the strobilurin, carboxamide, and demethylation inhibitor groups. Rapid directional selection toward fungicide resistance has been reported for strobilurin $(5,12,16,19)$ and carboxamide fungicides in other pathosystems $(1,20,21,42)$. These fungicides are considered medium-to-high risk for the selection of resistant strains by the Fungicide Resistance Action Committee. Moreover, reduced sensitivity to difenoconazole (a demethylation inhibitor fungicide) by isolates of $P$. ligulicola var. inoxydablis has been reported in Tasmanian pyrethrum fields (18).

In the absence of cost-effective alternatives to fungicide-based disease management programs, current recommendations for ray blight disease management include the application of fungicides to all pyrethrum fields because disease risk factors for ray blight are poorly understood, and both growers and the pyrethrum industry are risk averse. This is likely to result in the unnecessary application of fungicides, especially when the risk of economic injury is low. In a preliminary study, landscape aspect and elevation were both shown to have a significant effect on the risk of severe ray blight epidemics in the spring in Tasmania (33). Disease intensity in pyrethrum fields on north-facing slopes was significantly less than that on southfacing slopes. Similarly, the intensity of ray blight was lower in fields on the crests of hills than in fields in the valleys. Disease intensity of epidemics has also been correlated with the number of consecutive days with at least $0.1 \mathrm{~mm}$ of rain during early spring (37).

Quantitative estimates of the associations of environmental and site-risk factors with the intensity of ray blight epidemics remain poorly understood. Elucidating associations could further aid in avoiding high disease risk situations and provide the basis to make cost-effective disease man- 
agement decisions, such as the need for a late-spring (i.e., a third) fungicide application. Therefore, the objectives of this research were to quantify the associations of site-specific environmental and site-risk factors with the disease intensity of ray blight, and to develop quantitative models to predict the occurrence of economically damaging levels of this disease.

\section{MATERIALS AND METHODS}

Data collection. One hundred five pyrethrum fields (46 in 2003, 51 in 2004, and 8 in 2005) were arbitrarily selected from all pyrethrum production districts in Tasmania (Devonport, Central Coast, and Wynyard). A description of the field sites in 2003 and 2004 has been presented elsewhere (31). Fifteen of the fields included in the study in 2003 were also monitored in 2004. Fields included in the study were contained within a $150-\mathrm{km}$ range across the northwest coast of Tasmania between the eastern boundary of UTM coordinate 55G 4628995435784 and western boundary coordinate 3801465466162 , and no further than $30 \mathrm{~km}$ inland from the coast. At each field, latitude, longitude, and elevation were recorded using a hand-held global positioning system (GPS 72; Garmin International Inc., Olathe, KS). Within each field, one plot $(10 \mathrm{~m}$ long $\times 24 \mathrm{~m}$ wide) was established that did not receive any fungicides for the management of ray blight in spring. The remainder of the field received the industry recommended fungicide program (38). Fungicides were applied using standard tractor-mounted spray equipment at 300 liters/ha at a pressure of approximately $200 \mathrm{kPa}$.

The methodology used to assess disease intensity in fields sampled in 2003 and 2004 has been reported $(31,32)$, and this protocol was also followed in 2005. In the current study, disease intensity assessments were made during 12 to 16 September 2003, 7 to 12 October 2003, 8 to 12 September 2004, 6 to 11 October 2004, 5 to 6 September 2005, and 3 to 5 October
2005. Briefly, for each assessment, 20 flowering stems were systematically selected from each of three linear transects covering the entire width of each nontreated plot (60 stems per plot in total). Flowering stems were destructively sampled by cutting stems at the soil-line, and defoliation severity, defined as the length at which leaves were either completely necrotic or abscised divided by the total stem length (expressed as a percentage of total stem length) (32), was assessed on each stem in the laboratory within $48 \mathrm{~h}$ of collection. Disease data were summarized for each site as mean defoliation severity per sampling unit.

Yield losses in pyrethrum caused by ray blight occur primarily through the loss of healthy flowers $(35,36,38,40)$. Previous research using Tobit regression identified a threshold for defoliation severity beyond which the incidence of flowers with ray blight increases linearly to $38.2 \%( \pm 1.12)$. For this study, a classification criterion of $40 \%$ defoliation severity was defined as the minimal amount of disease to classify pyrethrum fields as having economically damaging levels of ray blight. This value was assigned based on practical considerations that a pyrethrum grower would be more likely to identify and classify fields using a $40 \%$ defoliation severity than the $38.2 \%$. Fields with defoliation severity below $40 \%$ were assigned a value of zero and those greater than or equal to the $40 \%$ defoliation severity were assigned a value of one to generate a binary response variable for use in subsequent statistical analyses (31).

For each pyrethrum field, site-specific agronomic variables were obtained by the pyrethrum industry from the growers and are summarized in Table 1. Testing of seed to quantify the incidence of seed infection by P. ligulicola var. inoxydablis was conducted using methodology described by Pethybridge et al. (39). Using global positioning systems and geographic information systems software, the centroids of

Table 1. Predictor variables assessed for their potential to predict the seasonal and site-specific disease risk factors for pyrethrum fields with defoliation severities $\geq 40 \%$ caused by ray blight in Tasmania, Australia

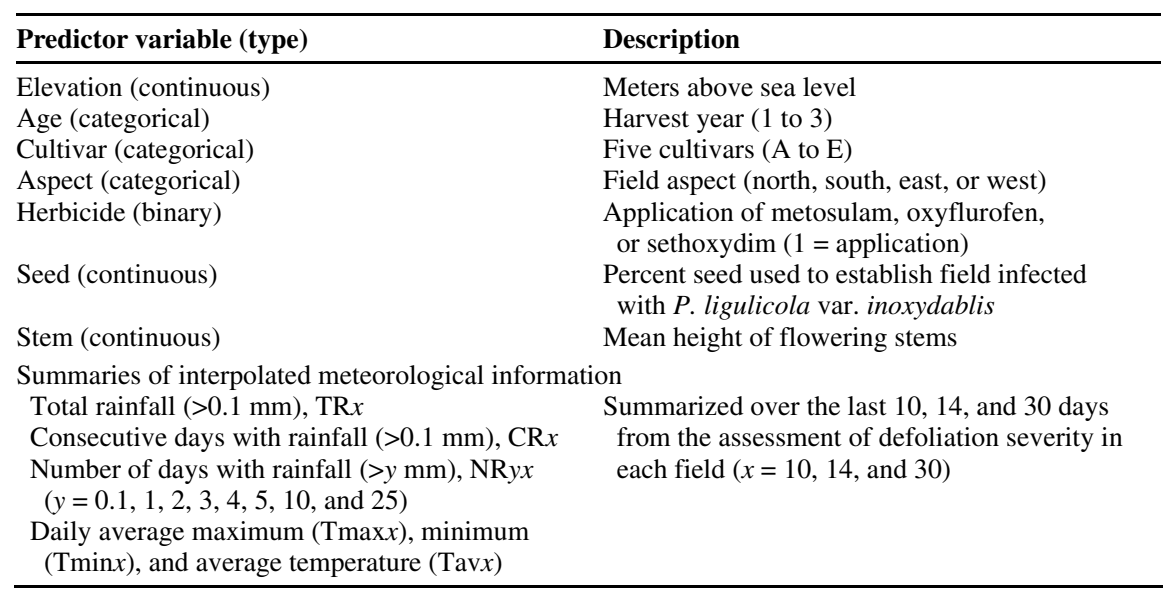

each pyrethrum field were used to obtain interpolated site-specific daily weather variables (temperature and rainfall) from the Queensland Department of Natural Resources and Mines Data Drill algorithm (17). The precision of interpolated temperature and rainfall data was $0.5^{\circ} \mathrm{C}$ and 1 $\mathrm{mm}$, respectively, at a spatial resolution of approximately $5 \mathrm{~km}^{2}(15,17,44)$. To quantify errors with the interpolated weather data, Pearson's correlation coefficient, mean error, and absolute mean error were calculated for the interpolated temperature and rainfall compared with meteorological information measured on-site for each of 12 locations across all production districts between 1 September and 31 October in 2003 and 2004 (Genstat 10, Version 1; Adept Scientific Inc., Bethesda, MD). Onsite meteorological information was collected using a Watchdog 450 data logger (Spectrum Technologies Inc., Plainfield, IL) fitted with internal air temperature $\left( \pm 0.7^{\circ} \mathrm{C}\right)$, relative humidity $( \pm 3 \%)$, and rainfall $( \pm 4 \mathrm{~mm})$ gauge. The data logger was placed in a solar radiation shield located $30 \mathrm{~cm}$ above soil level, which was approximately 5 to $10 \mathrm{~cm}$ above the pyrethrum canopy. Data were recorded at 30min intervals.

Data analyses. Correlations between each of the individual continuous variables with measurements of defoliation severity were tested by Spearman's rank correlation coefficients tests (8) using the CORR procedure in SAS version 9.1 (SAS Institute, Inc., Cary, NC). Kolmogorov-Smirnov two-sample test statistics were also calculated to compare the distribution of predictor variables between the defoliation severity groups using the NPAR1WAY procedure in SAS version 9.1 (SAS). Monte Carlo estimation was used to derive exact $P$ values for the Kolmogorov-Smirnov test.

Logistic regression was used to identify and quantify site-specific risk factors and develop predictive models for disease severity exceeding the Tobit regression defoliation severity level of $40 \%$. All 105 fields (data sets) were used for model development using data collected in September and October. These time periods were chosen because September is a period of rapid increase in disease severity (37) and coincides with the beginning of the spring fungicide program for ray blight management. October defoliation severity was chosen for model development because at this time growers may decide whether or not a third fungicide application is needed or cost-effective.

Logistic regression analyses were conducted using the LOGISTIC procedure in SAS. Candidate models were selected using stepwise, forward, and reverse variable selection methods (30). Model fit was evaluated by Akaike's Information Criterion (AIC) and the Hosmer and Lemeshow goodness of fit test. Model predictive ability was evaluated by correlation indices 
such as Somers' D rank correlation (43), Gamma, and the number of concordant and discordant pairs. Models with the least number of independent predictor variables were preferred to avoid model overspecification. Final models were selected based on percent correct classification, $\mathrm{AIC}$, the number of variables, and biological considerations.

Accuracy, sensitivity, and specificity (24) were calculated for the models. Accuracy was defined as the percentage of data sets classified correctly. Sensitivity was defined as the percentage of data sets where defoliation severity was greater than or equal to $40 \%$ (cases) that were classified correctly. Specificity was defined as the percentage of data sets where defoliation did not exceed $40 \%$ (controls) that were classified correctly.

Receiver operating characteristic (ROC) curve analysis. ROC curve analysis is a statistical procedure used to identify and evaluate predictors $(23,24)$, and can aid in selecting appropriate thresholds for operational use of a predictor $(45,46)$. In this study, ROC curve analysis was used to compare the logistic regression models and identify optimal predictor thresholds, defined as $D_{\text {thresh }}$, to minimize average management costs to growers. ROC curves were generated for each predictive model by plotting sensitivity (also referred to as the "true positive proportion", TPP) versus 1 - specificity (referred to as the "false positive proportion", FPP) and allowing the threshold to vary over the range of its possible values $(14,29)$. For a logistic regression model, a threshold refers to a predicted probability of group membership, which corresponds to a point on an ROC curve representing a value of TPP and FPP. One can succinctly express the ROC curve as TPP $=f(\mathrm{FPP})$, where $f(\cdot)$ is an arbitrary function. The area under the ROC curve (AUROC curve) and its standard error were calculated for each curve according to the methods of Hanley and McNeil (13) using MedCalc (MedCalc Software, Mariakerke, Belgium). The AU$\mathrm{ROC}$ is an overall measure of predictive ability and can assume values between 0 and 1 , and for a perfect predictor equals 1 (9). A more detailed account of the procedures can be found in Turechek et al. (45) and Madden (23).

Youden's index, $J$, was used to identify the threshold on the ROC curve that was furthest to the diagonal line representing a noninformative predictor. The index is calculated by $J=$ sensitivity + specificity - 1 (24), and the threshold giving the highest value of $J$ was considered the optimal threshold. A limitation of Youden's index is that it weights model sensitivity and specificity as equally important. Sensitivity and specificity, however, are not of equal importance to a grower (economically speaking) for the management of ray blight.
Hughes and Madden (14) described a cost function where its first derivate, $f^{\prime}$ (FPP), is used to identify the point on an ROC curve where average management costs are minimized for a given disease prevalence. Using the notation of Hughes and Madden (14),

$$
f^{\prime}(\mathrm{FPP})=\left(\frac{\mathrm{C}_{\mathrm{FP}}-\mathrm{C}_{\mathrm{TN}}}{\mathrm{C}_{\mathrm{FN}}-\mathrm{C}_{\mathrm{TP}}}\right) \cdot\left(\frac{1-P(D+)}{P(D+)}\right)
$$

where $\mathrm{C}_{\mathrm{FP}}, \mathrm{C}_{\mathrm{TN}}, \mathrm{C}_{\mathrm{FN}}$, and $\mathrm{C}_{\mathrm{TP}}$ are the costs associated with a false positive, true negative, false negative, and true positive decision, respectively, and $P(D+)$ is the prevalence or prior probability of disease exceeding a threshold value. The expression $\left(\mathrm{C}_{\mathrm{FP}}-\mathrm{C}_{\mathrm{TN}}\right) /\left(\mathrm{C}_{\mathrm{FN}}-\mathrm{C}_{\mathrm{TP}}\right)$ is referred to as the cost ratio, and provides a quantitative estimate of the relative costs of false positive and false negative predictions (23), and the term $(1-P(D+)) / P(D+)$ is the inverse odds ratio of the prevalence of disease and provides a measure of disease pressure.

For ray blight, the economic cost of an incorrect management decision due to a false negative (yield lost from failing to apply a third fungicide application when needed) is 34.7 times greater than the cost of a false positive (i.e., the cost of applying a third application of difenoconazole and chlorothalonil when not required) (S. J. Pethybridge, unpublished data). Actual values associated with the cost of false negatives and false positives are not presented for proprietary purposes. Assuming that the costs of true positive decisions and true negative decisions are 0 , the current cost ratio for ray blight is 0.029 (i.e., 1/34.7). An estimate of $P(D+)$ was calculated directly from the data by determining the proportion of fields where the defoliation severity in October exceeded $40 \%$ (i.e., 56 out of 105 fields). However, this estimate of $P(D+)$ may not represent the true prevalence of defoliation severity exceeding $40 \%$ in October in growers fields since it was calculated from research plots where fungicide applications were not made earlier in the season. Moreover, $P(D+)$ is unlikely to be constant, and may vary annually due to weather factors, intensity of disease management earlier in the season, or other production practices. Therefore, a range of values of $P(D+)$ was considered in calculations to determine optimal action thresholds as a function of $P(D+)$.

Average management costs are minimized at the point on the ROC curve (22) with slope $f^{\prime}$ (FPP) (49). Methodology for identifying this point has been described fully in Hughes and Madden (14) and Madden (23), and is not presented in detail here. Briefly, the empirical ROC curves were expressed in a functional (parametric) form using the equation of Lloyd (22). Shape parameters of the parametric ROC curves, defined as $\Delta$ and $\mu$, were estimated by nonlinear regression in SAS following equation 4 of Turechek and Wilcox (46). TPP and FPP were estimated algebraically from the ROC curve $(\mathrm{TPP}=f(\mathrm{FPP}))$ corresponding to the $f^{\prime}(\mathrm{FPP})$ point, as described previously (23). From TPP and FPP, the corresponding optimal economic "cut-point" was determined. A cut-point is a point on an ROC curve used to dichotomize predictions of a continuous variable into categories, in this case model predictions of whether a field will or will not have a severe epidemic of ray blight.

Evaluating a predictor based on posterior probabilities. Sensitivity and specificity are useful statistics in the development and evaluation of a predictor, but their interpretation is ultimately linked to the a priori knowledge of the true status of the data (i.e., whether one is confronted with a case or a control), which is rarely known in practice. What is of most interest are the posterior probabilities of disease exceeding a management threshold given that the prediction of disease has or has not exceeded a predictive threshold (47). An intuitive expression of posterior odds of an event can be defined with an alternative formulation of Bayes' theorem (23). The odds of disease exceeding $D_{\text {thresh }}$ given a positive prediction is expressed: $\operatorname{odds}(D+\mid T+)=\operatorname{odds}(D+) \times L R(+)$, where $\operatorname{odds}(D+)=P(D+) /(1-P(D+))$ and $L R(+)$ $=\mathrm{TPP} / \mathrm{FPP}=$ sensitivity $/(1-$ specificity $)$ is the likelihood ratio of a positive prediction. Similarly, the odds of disease exceeding $D_{\text {thresh }}$ given a negative prediction is: $\operatorname{odds}(D+\mid T-)=\operatorname{odds}(D+) \times L R(-)$, where $L R(-)=$ FNP/TNP $=(1-$ sensitivity)/specificity is the likelihood ratio of a negative prediction. If $L R(+)>1$, the odds of disease exceeding $D_{\text {thresh }}$ subsequent to a positive prediction is greater than the odds prior to the prediction. Similarly, if $L R(-)$ $<1$, the odds of disease exceeding $D_{\text {thresh }}$ subsequent to a negative prediction is less than the odds prior to the prediction. Thus, the best predictors are those in which $L R(+)>1$ and $L R(-)<1$ are met simultaneously. For any select cut-point of the predictor, the likelihood ratios can be shown graphically on the ROC plot (6). Specifically, the slope of the line extending from the origin to the cut-point is $L R(+)$. The line with steepest slope has the highest $L R(+)$. The line extending from the cutpoint to the point $(1,1)$ is $L R(-)$. The line with the shallower slope has the highest $L R(-)$. For each predictor, the positive and negative likelihood ratios were calculated for the cut-points identified by Youden's index and for the cut-points that minimized average management costs.

The odds statement also can be rearranged to express posterior probabilities using the relation $P(D \mid x)=\operatorname{odds}(D \mid x) /$ [odds $(D \mid x)+1]$. The probability $P(D+\mid T+)$, where $T+$ indicates a positive prediction by the model, is known as the positive predictive value (PPV). Similarly, the probability 
$P(D-\mid T-)$ is known as the negative predictive value (NPV). PPV and NPV were calculated for the optimal threshold of the predictor identified by minimizing equation 1 over a range of values of $P(D+)$.

\section{RESULTS}

Relationships between interpolated and on-site daily temperature and rainfall information. Positive correlations between interpolated and on-site weather variables were found $(P<0.001)$ over the 12 locations and 2 years of meteorological information in September and October, with mean Pearson correlation coefficients (r) of 0.85 and 0.51 for daily average temperature and rainfall, respectively (Table 2 ). Mean error and mean absolute error for daily mean temperature were $-0.17^{\circ} \mathrm{C}$ (range -4.26 to 3.91 ) and $0.96^{\circ} \mathrm{C}$ (range 0 to 3.91 ), respectively, where a positive value indicates the measured temperature was greater than the interpolated temperature. For rain, mean error and mean absolute error between the measured and interpolated data were $0.49 \mathrm{~mm}$ (range -23.7 to 53.1 ) and $1.79 \mathrm{~mm}$ (range 0 to 53.1 ), respectively (Table 2). Although the range of errors for rain was large on some individual days, daily mean errors and mean absolute errors were relatively small. Interpolated weather data were, therefore, used as the primary source of meteorological data for this study, considering the logistical difficulties in attempting to maintain and download data loggers to obtain on-site weather data for all 105 fields.

Logistic regression analysis. Over the 3 years of this study, 43 pyrethrum fields had defoliation severity values that met or exceeded $40 \%$ in September. In October, 56 of the 105 pyrethrum fields had defoliation severity values above $40 \%$. Fields with defoliation severity above $40 \%$ occurred in both months across all production districts. Strong positive correlations were detected among some continuous predictor variables indicating multicollinearity (Table 3). In these cases, only one of the predictor variables that were found to be collinear were included in the final models selected based on assessments of model accuracy, sensitivity, specificity, and AIC. Using the Kolmogorov-Smirnov twosample test, the distributions of all final predictor variables in both September and October models, with the exception of stem height in September, were found to be significantly different from the explanatory defoliation severity categories (Figs. 1 and 2). The latter predictor variable (stem

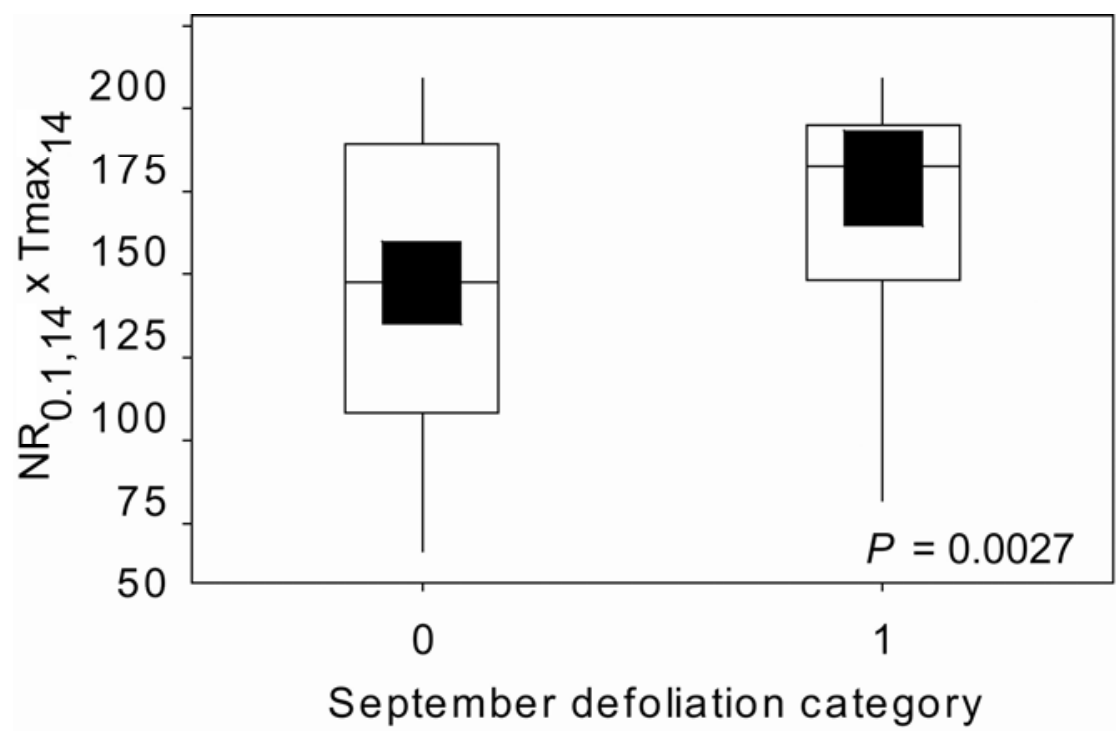

Fig. 1. Box plots of the predictor variable, the product of the number of days with rainfall $\geq 0.1 \mathrm{~mm}$ in the last 14 days $\left(\mathrm{NR}_{0.1,14}\right)$ and average maximum temperature in the last 14 days $\left(\operatorname{Tmax}_{14}\right)\left(\mathrm{NR}_{0.1,14} \times\right.$ $\operatorname{Tmax}_{14}$ ). Box plots show the median (line in boxes), middle $50 \%$ of the data (open box), confidence interval for the median based on the nonparametric sign-test (solid bar inside box), extremes of the data points (whiskers), and outliers (solid circles). Probabilities indicate the significance of the Kolmogorov-Smirnov two-sample test.

Table 2. Mean deviation and correlation of measured daily mean temperature and rain and interpolated daily mean temperature and rain estimated by the Data Drill algorithm (17)

\begin{tabular}{|c|c|c|c|c|c|c|c|c|c|c|}
\hline \multirow[b]{2}{*}{$n$ (days) } & \multicolumn{5}{|c|}{ Daily sum rain $(\mathbf{m m})$} & \multicolumn{5}{|c|}{ Daily mean temperature $(C)$} \\
\hline & Mean $\Delta$ Rain $^{\mathrm{a}}$ & Range & Mean $\mid \Delta$ Rain $\left.\right|^{\mathbf{a}}$ & Range & $r^{\mathbf{b}}$ & $\operatorname{Mean} \Delta \mathbf{T}^{\mathrm{a}}$ & Range & $\operatorname{Mean}|\Delta \mathbf{T}|^{\mathrm{a}}$ & Range & $r^{\mathbf{b}}$ \\
\hline 721 & 0.49 & -23.7 to 53.1 & 1.79 & 0 to 53.1 & 0.51 & -0.17 & -4.26 to 3.91 & 0.96 & 0 to 3.91 & 0.85 \\
\hline
\end{tabular}

a $\Delta$ Rain and $\Delta \mathrm{T}$ are the mean deviation in daily sum of rain and mean temperature, respectively, between measured and interpolated weather elements. Mean absolute errors in daily sum of rain and mean temperature are represented by $\mid \Delta$ Rain $\mid$ and $|\Delta \mathrm{T}|$, respectively.

${ }^{\mathrm{b}} r$ is the correlation coefficient to quantify the strength of the association between interpolated and measured daily rainfall and mean temperature $(P<$ $0.001)$.

Table 3. Multicollinearity measured by Spearman's rank $(\rho)$ correlation coefficients between continuous predictor variables used in September and October logistic regression models for ray blight of pyrethrum

\begin{tabular}{|c|c|c|c|c|c|c|}
\hline & \multicolumn{6}{|c|}{ Predictor variable $\mathrm{e}^{\mathrm{a}, \mathrm{b}}$} \\
\hline & Defol $_{\text {Oct }}$ & $\begin{array}{c}\mathrm{NR}_{1,14} \\
\text { (September) }\end{array}$ & Stem $_{\text {Sept }}$ & Defol $_{\text {Sept }}$ & $\begin{array}{c}\mathrm{NR}_{10,30} \\
\text { (October) }\end{array}$ & $\begin{array}{c}\mathrm{NR}_{0.1,14} \\
\text { (September) }\end{array}$ \\
\hline $\begin{array}{l}\mathrm{NR}_{1,14} \\
\text { (September) }\end{array}$ & $-0.31(0.001)$ & & $\ldots$ & $\ldots$ & $\ldots$ & $\ldots$ \\
\hline Stem $_{\text {Sept }}$ & $-0.024(0.817)$ & $0.319(0.001)$ & $\ldots$ & $\ldots$ & $\ldots$ & $\ldots$ \\
\hline Defol $_{\text {Sept }}$ & $0.219(0.032)$ & $-0.271(0.008)$ & $-0.044(0.669)$ & $\ldots$ & $\ldots$ & $\ldots$ \\
\hline $\begin{array}{l}\mathrm{NR}_{10,30} \\
\text { (October) }\end{array}$ & $-0.024(0.806)$ & $0.383(<0.001)$ & $-0.127(0.22)$ & $-0.268(0.008)$ & $\ldots$ & $\ldots$ \\
\hline $\begin{array}{l}\mathrm{NR}_{0.1,14} \\
\text { (September) }\end{array}$ & $-0.162(0.101)$ & $0.008(0.932)$ & $0.324(0.001)$ & $0.308(0.002)$ & $-0.54(<0.001)$ & \\
\hline $\mathrm{NR}_{10,30} \times$ Defol $_{\text {Sept }}$ & $0.186(0.069)$ & $0.198(0.065)$ & $-0.19(0.065)$ & $0.238(0.012)$ & $0.799(<0.001)$ & $-0.368(<0.001)$ \\
\hline
\end{tabular}

${ }^{a}$ Defol $_{\text {Oct }}=$ defoliation severity in October. $\mathrm{NR}_{0.114}=$ number of days with rainfall $\geq 0.1 \mathrm{~mm}$ in the last 14 days in September. $\mathrm{NR}_{1,14}=$ number of days with rainfall $\geq 1 \mathrm{~mm}$ in the last 14 days in September. Stem Sept $=$ stem height in September. $\mathrm{NR}_{10,30} \times$ Defol $_{\text {Sept }}=$ number of days with rainfall $\geq 10 \mathrm{~mm}$ in the last 30 days $\times$ defoliation severity in September.

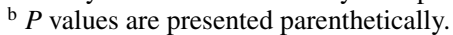


height in September) was included in the final model because of biological considerations of the effect of spring plant growth on ray blight (40) and due to higher model sensitivity when this variable was included.

Logistic regression for the September model included the product of the number of days with rainfall $\geq 0.1 \mathrm{~mm}\left(\mathrm{NR}_{0.1,14}\right)$ and the average maximum temperature in the last 14 days $\left(\operatorname{Tmax}_{14}\right)$ (Table 4). Accuracy, sensitivity, and specificity of the September model were $64.8,55.8$, and $71.0 \%$, respectively. For the October model, the predictor variables selected were the number of days with $\geq 1 \mathrm{~mm}$ of rain in the last 14 days $\left(\mathrm{NR}_{1,14}\right)$, stem height in September $\left(\mathrm{Stem}_{\mathrm{Sept}}\right)$, and the product of the number of days with at least $10 \mathrm{~mm}$ of rain in the last 30 days $\left(\mathrm{NR}_{10,30}\right)$ and defoliation severity in September ( Defol $_{\text {Sept }}$ ). Measurements of stem height in September were not available for 10 fields, which reduced the total number of data sets to 95 in the final model. Among these 95 data sets, 42 fields had defoliation severity less than $40 \%$ (controls) and 53 fields had defoliation severity greater than or equal to the threshold (cases). The October model with predictors $\mathrm{NR}_{1,14}$, Stem ${ }_{\text {Sept }}$, and $\mathrm{NR}_{10,30} \times$ Defol $_{\text {Sept }}$ had accuracy, sensitivity, and specificity of 72.6, 73.6, and $71.4 \%$, respectively. Maximum likelihood parameter estimates for each of the predictor variables and intercepts used in the final logistic regression models are presented in Table 4. The Hosmer and Lemeshow goodness-of-fit tests for the models were nonsignificant for the September model $(P$ $=0.083)$ and October model $(P=0.162)$, indicating an adequate fit of the models.

Receiver operating curve analysis. ROC curves for September and October models are shown in Figure $3 \mathrm{~A}$ and $\mathrm{B}$, respectively. The AUROC values for each model and associated statistics are presented in Table 5. Comparisons of the AUROC indicated that these models had overall similar predictive abilities $(P=0.061)$.

For each model, Youden's index was calculated for each of the cut-points, with the cut-point having the maximum value of $J$ being identified as the optimal cut-point. The cut-points identified correspond to model prediction probabilities thresholds of 0.25 and 0.57 for the September and October models, respectively. For example, when the probability of disease exceeds 0.57 in October, defoliation would be predicted and a third spray would be recommended. Plots of likelihood ratios for the thresholds identified by Youden's index indicated the October model had superior predictive ability for positive predictions compared to the September model (Fig. 3C and D). This is shown by the steeper slopes of the lines for the positive likelihood ratio $(L R+)$. The logistic regression model for September had superior negative predictive ability (Fig. 3C), as depicted by the shallower slope of the line for the negative likelihood ratio ( $L R-)$.

For the October model, the prediction threshold that minimized average management costs was lower than that identified by Youden's index. The optimal eco-
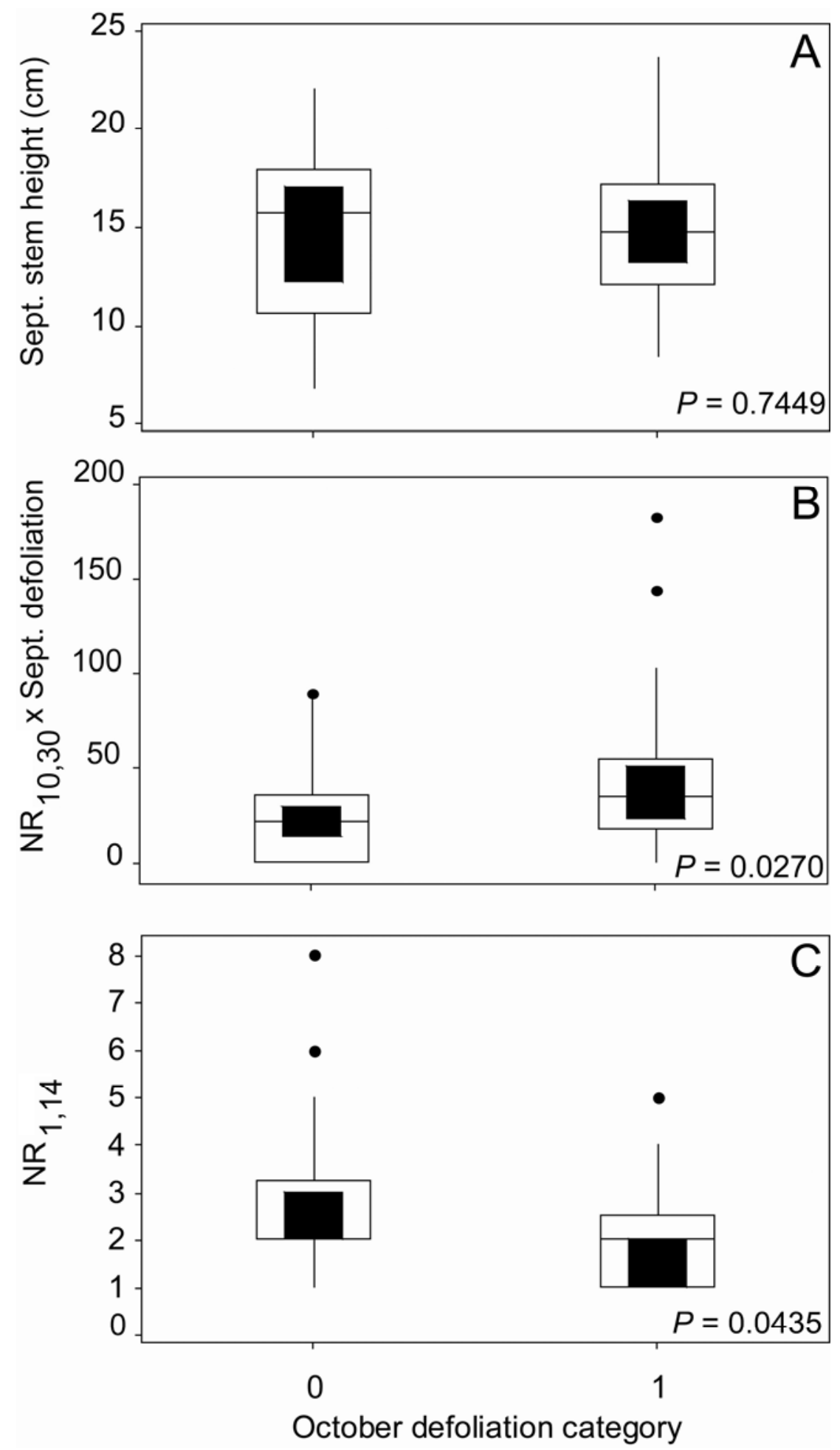

Fig. 2. Box plots of predictor variables for October defoliation categories caused by ray blight of pyrethrum in Tasmania, Australia. A, September stem height; B, number of days with rainfall $\geq 10 \mathrm{~mm}$ in the last 30 days $\left(\mathrm{NR}_{10,30}\right) \times$ defoliation severity in September; and $\mathbf{C}$, number of days with rainfall $\geq 1$ $\mathrm{mm}$ in the last 14 days $\left(\mathrm{NR}_{1,14}\right)$. Box plots show the median (line in boxes), middle $50 \%$ of the data (open box), confidence interval for the median based on the nonparametric sign-test (solid bar inside box), extremes of the data points (whiskers), and outliers (solid circles). Probabilities indicate the significance of the Kolmogorov-Smirnov two-sample test. 
point $(1,1)$ located in the upper right quadrant of the ROC curve, and indicate the need for routine treatment rather than treatment based on model predictions be- cause the risk of disease is too high and the potential losses are too great. Optimum prediction thresholds were greater than zero when $P(D+)$ was less than 0.2 , al-

Table 4. Maximum likelihood parameter estimates for predictor variables selected for logistic regression models for September and October ray blight defoliation severity

\begin{tabular}{lccc}
\hline $\begin{array}{l}\text { Model and } \\
\text { predictor variables }^{\mathbf{a}}\end{array}$ & Parameter estimate & Standard error & Wald Chi-square $^{\mathbf{b}}$ \\
\hline $\begin{array}{l}\text { September } \\
\mathrm{NR}_{0.1,14} \times \operatorname{Tmax}_{14}\end{array}$ & 0.021 & & \\
$\mathrm{Intercept}^{\text {October }}$ & -3.17 & 0.006 & $11.554(<0.001)$ \\
$\mathrm{NR}_{1,14}$ & -1.152 & 0.876 & $13.085(<0.001)$ \\
$\mathrm{Stem}_{\text {Sept }}$ & 0.2150 & 0.276 & $17.407(<0.001)$ \\
$\mathrm{NR}_{10,30} \times$ Defol $_{\text {Sept }}$ & 0.0516 & 0.078 & $7.681(0.006)$ \\
Intercept & -1.719 & 0.014 & $13.370(<0.001)$ \\
\end{tabular}

${ }^{\text {a }} \mathrm{NR}_{0.1,14}=$ number of days with rainfall $\geq 0.1 \mathrm{~mm}$ in the last 14 days. $\operatorname{Tmax}_{14}=$ average maximum temperature in the last 14 days. $\mathrm{NR}_{1,14}=$ number of days with rainfall $\geq 10 \mathrm{~mm}$ in the last 14 days. Stem $\mathrm{Sept}_{\text {S }}=$ stem height in September. $\mathrm{NR}_{10,30} \times$ Defol $_{\text {Sept }}=$ number of days with rainfall $\geq 1 \mathrm{~mm}$ in the last 30 days $\times$ defoliation severity in September.

${ }^{\text {b }} P$ values are presented parenthetically. Hosmer and Lemeshow goodness-of-fit tests for the logistic regression models were nonsignificant for the September model $(P=0.083)$ and October model $(P=$ 0.162 ), indicating an adequate fit of the models.

though the optimum prediction threshold did not exceed 0.43 for any level of $P(D+)$ greater than 0 (Fig. 4). In other words, if the prior probability of disease is less than 0.2 , the model should be used to schedule a treatment.

The positive and negative predictive values varied in relation to the prevalence of ray blight as expected (Fig. 4). PPV ranged from 0.03 to 0.32 for values of $P(D+)$ in the range of 0.01 to 0.5 . PPV of the model was less than $P(D+)$ for values of $P(D+)$ greater than 0.2 , indicating the probability that a positive prediction by the model is a "true" positive was less than the prior probability of disease. Negative predictive value of the model ranged from 0.99 to 0.94 for the same range of $P(D+)$, with NPV increasing as $P(D+)$ decreased.

\section{DISCUSSION}

Results of this study identified weather and other site-specific factors that impact the risk of ray blight defoliation exceeding
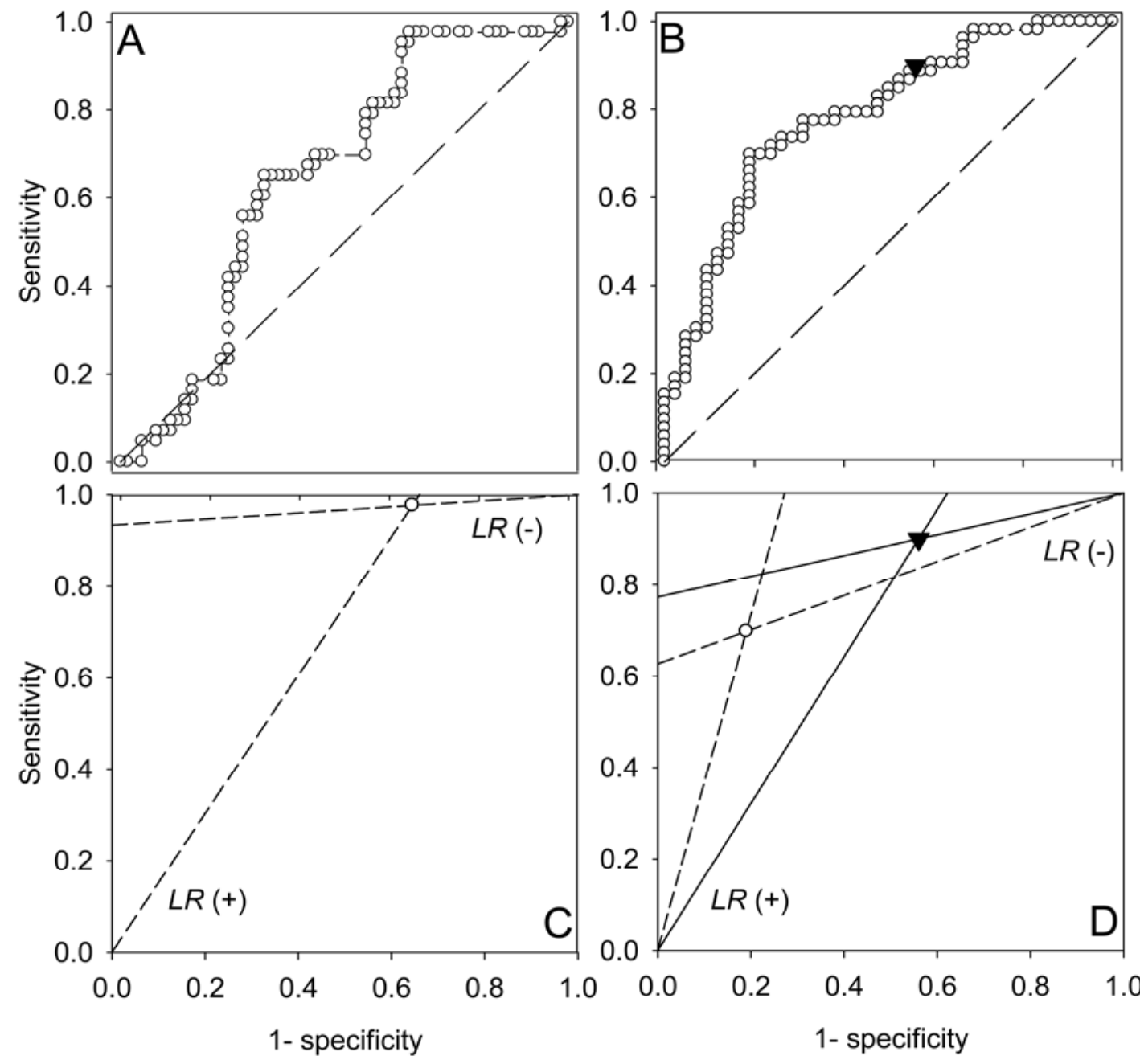

Fig. 3. A and B, Receiver operating characteristic (ROC) curves for logistic regression models for classifying defoliation severity caused by ray blight of pyrethrum in Tasmania, Australia. The long dashed line in $\mathbf{A}$ and $\mathbf{B}$ is the line representing a noninformative predictor (i.e., predictions no better than by chance). C and D, Graphical representation of the positive $(L R(+))$ and negative likelihood ratios $(L R(-))$ for thresholds of the predictors identified by Youden's index. Open circles in $\mathbf{C}$ and $\mathbf{D}$ indicate the thresholds of the predictors identified by Youden's index. For a given threshold, the slope of the line extending from the origin to the threshold is $L R(+)$. The line with the steepest slope has the highest $L R(+)$. The line extending from the threshold to the point $(1,1)$ is $L R(-)$. The line with the shallower slope has the highest $L R(-)$. The triangles in $\mathbf{B}$ and $\mathbf{D}$ represent thresholds of the predictors that minimize average management costs. Panels $\mathbf{A}$ and $\mathbf{C}$ are for September defoliation severity models, and panels $\mathbf{B}$ and $\mathbf{D}$ are for October defoliation severity models. 
$40 \%$ - a level of defoliation associated with a linear increase in the loss of flowers due to ray blight (31). For the September model, the product of the number of days with rainfall $\geq 0.1 \mathrm{~mm}$ and average maximum temperature during the last 14 days was a significant predictor of ray blight severity in September. Achieving accurate models to estimate the risk of September defoliation was more difficult than achieving accurate October-based models. For October models, the inclusion of some measurement of host growth or disease in the earlier sampling period in September (e.g., stem height and defoliation severity) also was important. Stem height is thought to be related to disease development because young stems are highly susceptible to tip dieback in early spring (37). For example, if stems are shorter because of injury from frosts or herbicides, then ray blight epidemics are generally delayed. On the other hand, disease intensity has been found to decrease beginning in midOctober due to either a reduction in the number of consecutive days with rain, host growth exceeding pathogen reproduction and disease development, and/or stems becoming less susceptible to infection as they age $(32,37)$.

The information presented in this research builds upon preliminary results that indicated that landscape features of fields such as aspect and elevation were risk factors in determining disease severity (33). Pethybridge and Hay (33) identified crops on north-facing slopes and on the crests of hills as having a significantly lower risk for high disease severity compared to pyrethrum fields located on southfacing slopes and in valleys. Inclusion of aspect and/or elevation in the models with predictor variables in Table 3 reduced the sensitivity of the models and increased AIC. This indicates that aspect and elevation did not improve model performance when the other predictor variables were considered. Based on the results of the current study, slope direction and aspect were most likely underlying risk factors related to variables identified in this study, previously suggested by Pethybridge and Hay (33).

Site-specific factors evaluated that were not significantly associated with disease risk in this study included crop age, cultivar, and agronomic factors (such as herbicide application). Interestingly, the incidence of $P$. ligulicola var. inoxydablis in the seed used to establish the crop was not found to be an important predictor variable for ray blight severity in this study. Earlier studies had demonstrated a significant linear relationship between defoliation severity within spring crops and the incidence of P. ligulicola var. inoxydablis in the harvested seed (39). The ability to assess the role of this source of primary inoculum in subsequent epidemics was not possible in this study since all seedlots had at least $1 \%$ incidence of $P$. ligulicola var. inoxydablis, and therefore, all pyrethrum fields may have had adequate seedborne inoculum to initiate severe epidemics if rainfall and temperature were favorable. This also raises questions about the critical threshold over which the incidence of infested seed is unacceptable. Alternatively, other sources of inoculum (e.g., soil, airborne spores) may be widespread in pyrethrum fields, and seedborne inoculum may not be essential to initiate epidemics.

This study has also found that interpolated site-specific rainfall and temperature data could be accurately estimated in northern Tasmania using the Data Drill system of the Australian Bureau of Meteorology. Errors associated with interpolated weather data were relatively small compared to measured weather elements when calculated on a daily basis. These errors were likely due to both errors in the kriging interpolation procedure of Data Drill and canopy microclimate effects that are not considered in this algorithm (17).
As shown for other interpolated meteorological data services (e.g., SkyBit) (25), Data Drill may provide a useful tool for site-specific estimation of these variables for future disease prediction studies and operational deployment of certain disease forecast models.

Receiver operating characteristic curves were used to evaluate and compare the predictive power of the logistic regression models, and for the identification of optimal thresholds. The optimal cut-point on the ROC curve identified using Youden's index corresponded to a predictive threshold of 0.57 for the October logistic regression model, which was considerably higher that the optimal cut-point when economic considerations and disease prevalence were considered. The latter procedure integrates the costs of decisions based on the probabilities of making false positive and negative decisions and prior probability of disease occurring at levels sufficient to cause economic damage (i.e., $40 \%$ defoliation severity) to arrive at a threshold that mini-

Table 5. Summary statistics for receiver operating characteristic curves generated for logistic regression models for classifying September and October defoliation severity of ray blight of pyrethrum in Tasmania, Australia

\begin{tabular}{lcccc}
\hline Model $^{\mathbf{a}}$ & Controls $^{\mathbf{b}}$ & Cases $^{\mathbf{b}}$ & AUROC $^{\mathbf{c}}( \pm \mathbf{s e})$ & $\begin{array}{c}\text { 95\% confidence } \\
\text { interval }\end{array}$ \\
\hline September & 62 & 43 & $0.65( \pm 0.056)$ & 0.55 to 0.74 \\
October & 42 & 53 & $0.78( \pm 0.046)$ & 0.69 to 0.86 \\
\hline
\end{tabular}

a There were a total of 105 data sets for the September model and 95 for the October model due to missing data for one of the predictor variables (September stem height) for 10 fields.

${ }^{\mathrm{b}}$ Control refers to fields with defoliation severity less than $40 \%$. Case refers to fields with defoliation severity of at least $40 \%$.

c Area under the receiver operating characteristic curve.

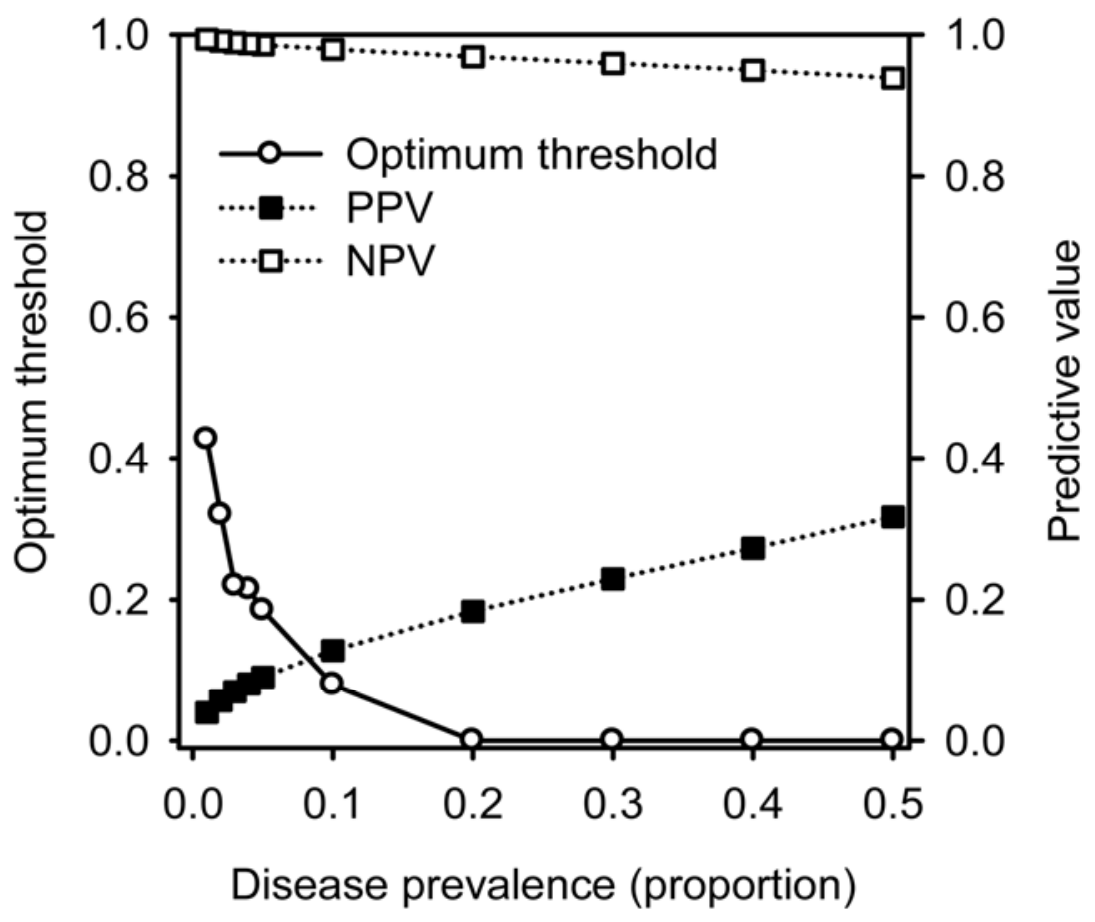

Fig. 4. Optimum decision threshold, negative predictive value (NPV), and positive predictive value (PPV) in relation to prevalence of ray blight disease of pyrethrum for a logistic regression model to classify severity of ray blight epidemics. A cost ratio of 0.029 was assumed for management of the disease with a fungicide application in October. 
mizes average costs to the grower. Management based on the economic threshold indicated that average management costs will be minimized when the third fungicide application is made routinely, independent of model predictions, when disease prevalence is greater than 0.2 . This suggests that growers' standard practice of routinely applying a third fungicide treatment may be economically justified, depending on disease prevalence, which is difficult to estimate accurately in practice. Likewise, this also suggests that use of the model could reduce management costs when disease prevalence is expected to be less than 0.2 . This information could be incorporated into a decision-support aid to assist growers in making correct decisions concerning the need for a third fungicide application in October. This could help to minimize unnecessary fungicide applications at low risk cropping sites to reduce variable production costs incurred by growers and lessen directional selection toward fungicide resistance. Thorough, individualized cost-benefit analyses are likely necessary to customize model prediction thresholds for specific situations based on current crop price functions and disease intensity (46).

No quantitative information currently exists from controlled environment studies on the role of moisture and temperature on disease components in the pyrethrum-ray blight pathosystem (e.g., infection efficiency, incubation period, lesion expansion, latent period, and sporulation capacity). Moisture and temperature requirements have been described for the anamorph and teleomorph developmental stages of chrysanthemum ray blight, caused by the closely related fungus $P$. ligulicola var. ligulicola $(27,28)$. In this pathosystem, production of pycnidia is correlated with periods of high moisture (28), and when wet conditions coincide with optimal temperatures (i.e., $26^{\circ} \mathrm{C}$ ), conidia can be produced in 3-day-old lesions. McCoy and Dimock (27) demonstrated that ascospore liberation could occur with just $0.1 \mathrm{~mm}$ moisture accumulation. These relationships formed the basis for a plant disease simulator known as MYCOS (26). Elucidation of how temperature and moisture influence disease components in ray blight of pyrethrum would assist in the development of models based on the interaction of environmental variables, the host, and pathogen. Given the high cost of a false negative error in this system, any predictive system for ray blight must be extremely accurate to reduce average management costs for the disease when disease prevalence is much greater than 0 .

\section{ACKNOWLEDGMENTS}

We gratefully acknowledge the pyrethrum growers who allowed access to their crops for field trials and technical assistance of Craig Palmer. This project was funded by Botanical Resources Austra- lia Pty. Ltd., the Australian Research Council Linkage program (LP0560562), and USDA-ARS CRIS 6618-22000-034-00 and 5358-21000-035-00.

\section{LITERATURE CITED}

1. Avenot, H. F., and Michailides, T. J. 2007. Resistance to boscalid fungicide in Alternaria alternata isolates from pistachio in California. Plant Dis. 91:1345-1350.

2. Baker, K. F., and Davis, L. H. 1959. Ascochyta disease of chrysanthemum appears in California. Calif. State Florists Assoc. Mag. 8:A-B.

3. Baker, K. F., Dimock, A. W., and Davis, L. H. 1949. Life history and control of the Ascochyta ray blight of chrysanthemum. Phytopathology 39:789-805.

4. Baker, K. F., Dimock, A. W., and Davis, L. H. 1961. Cause and prevention of the rapid spread of the Ascochyta disease of chrysanthemum. Phytopathology 51:96-101.

5. Bartlett, D. W., Clough, J. M., Godwin, J. R., Hall, A. A., Hamer, M., and Parr-Dobrzanski, B. 2002. The strobilurin fungicides. Pest Manag. Sci. 58:649-662.

6. Biggerstaff, B. J. 2000. Comparing diagnostic tests: A simple graphic using likelihood ratios. Stats. Med. 19:649-663.

7. Brown, P. H., and Menary, R. C. 1994. Flowering in pyrethrum (Tanacetum cinerariaefolium L.): I. Environmental requirements. J. Hortic. Sci. 69:877-884.

8. Cohen, J., Cohen, P., West, S. G., and Aiken, L. S. 2003. Applied Multiple Regression/Correlation Analyses for the Behavioral Sciences. 3rd ed. Lawrence Erlbaum Associates, Hillsdale, NJ.

9. DeLong, E. R., DeLong, D. M., and ClarkPearson, D. L. 1988. Comparing the areas under two or more correlated receiver operating characteristic curves: A nonparametric approach. Biometrics 44:837-845.

10. Elliott, M. 1995. Chemicals in insect control. Pages 3-31 in: Pyrethrum Flowers: Chemistry, Toxicology and Uses. J. E. Casida and G. B. Quistad, eds. Oxford University Press, New York

11. Fox, R. T. V. 1998. Chrysanthemum ray blight. Mycologist 12:135-136.

12. Gisi, U., Chin, K. M., Knapova, G., Farber, R. K., Mohr, U., Parisi, S., Sierotzki, H., and Steinfeld, U. 2000. Recent developments in elucidating modes of action of resistance to phenylamide, DMI, and strobilurin fungicides. Crop Prot. 19:836-872.

13. Hanley, J. A., and McNeil, B. J. 1982. The meaning and use of the area under the receiver operating characteristic (ROC) curve. Radiology 143:29-36.

14. Hughes, G. H., and Madden, L. V. 2003. Evaluating predictive models with application in regulatory policy for invasive weeds. Agric. Syst. 76:755-774.

15. Hutchinson, M. F. 1995. Interpolating mean rainfall using thin plate smoothing splines. Int. J. Geographical Inf. Syst. 9:385-403.

16. Ishii, H., Fraaije, B. A., Sugiyama, T., Noguchi, K., Nishimura, K., Takeda, T., Amano, T., and Hollomon, D. W. 2001. Occurrence and molecular characterization of strobilurin resistance in cucumber powdery mildew and downy mildew. Phytopathology 91:1166-1171.

17. Jeffrey, S. J., Carter, J. O., Moodie, K. M., and Beswick, A. R. 2001. Using spatial interpolation to construct a comprehensive archive of Australian climate data. Environ. Model. Software 16:309-330.

18. Jones, S., Pethybridge S. J., Hay, F. S., Groom, T., and Wilson, C. R. 2007. Baseline sensitivity of Australian Phoma ligulicola isolates from pyrethrum to azoxystrobin and difenoconazole. J. Phytopathol. 155:377-380.

19. Köller, W., Parker, D. M., Turechek, W. W., Avila-Adame, C., and Cronshaw, K. 2004. A two-phase resistance response of Venturia in- aequalis populations to the QoI fungicides kresoxim-methyl and trifloxystrobin. Plant Dis. 88:537-544.

20. Kulka, M., and von Schmelling, B. 1987. Carboxin fungicides and related compounds. Pages 120-131 in: Modern Selective Fungicides: Properties, Applications, Mechanisms of Action. H. Lyr, ed. John Wiley \& Sons, New York.

21. Leroux, P. 1986. Caractéristiques des souches d'Ustilago nuda, agent du charbon nu de l'orge résistantes à la carboxine. Agronomie 6:225-226.

22. Lloyd, C. J. 2000. Regression models for convex ROC curves. Biometrics 56:862-867.

23. Madden, L. V. 2006. Botanical epidemiology: Some key advances and its continuing role in disease management. Eur. J. Plant Pathol. 115:3-23.

24. Madden, L. V., Hughes, G., and van den Bosch, F. 2007. The Study of Plant Disease Epidemics. American Phytopathological Society, St. Paul, MN

25. Magarey, R. D., Seem, R. C., Russo, J. M., Zack, J. W., Waight, K. T., Travis, J. W., and Oudemans, P. V. 2001. Site-specific weather information without on-site sensors. Plant Dis. 85:1216-1226.

26. McCoy, R. E. 1971. Epidemiology of chrysanthemum Ascochyta blight. Ph.D. diss. Cornell University, Ithaca, NY.

27. McCoy, R. E., and Dimock, A. W. 1973. Environmental factors regulating ascospore discharge by Mycosphaerella ligulicola. Phytopathology 63:586-589.

28. McCoy, R. E., Horst, R. K., and Dimock, A. W. 1972. Environmental factors regulating sexual and asexual regulation by Mycosphaerella ligulicola. Phytopathology 62:1188-1195.

29. Metz, C. E. 1978. Basic principles of ROC analysis. Nucl. Med. 8:283-298.

30. Morrison, D. F. 1976. Multivariate Statistical Methods. McGraw-Hill, New York.

31. Pethybridge, S. J., Esker, P., Dixon, P., Hay, F., Groom, T., Wilson, C., and Nutter, F. W., Jr 2007. Quantifying loss caused by ray blight disease in Tasmanian pyrethrum fields. Plant Dis. 91:1116-1121.

32. Pethybridge, S. J., Esker, P., Hay, F., Wilson, C., and Nutter, F. W., Jr. 2005. Spatiotemporal description of epidemics caused by Phoma ligulicola in Tasmanian pyrethrum fields. Phytopathology 95:648-658.

33. Pethybridge, S. J., and Hay, F. S. 2001. Influence of Phoma ligulicola on yield and site factors on disease development in Tasmanian pyrethrum crops. Aust. Plant Pathol. 30:1720.

34. Pethybridge, S. J., Hay, F. S., Esker, P. D., Gent, D. H., Wilson, C. R., Groom, T., and Nutter, F. W. Jr. 2008. Diseases of pyrethrum in Tasmania: Challenges and prospects for management. Plant Dis. 92:1260-1272.

35. Pethybridge, S. J., Hay, F. S., Esker, P. D., Groom, T., Wilson, C. R., and Nutter, F. W., Jr. 2008. Visual and radiometric assessments for yield losses caused by ray blight in pyrethrum. Crop Sci. 48:343-352.

36. Pethybridge, S. J., Hay, F., Esker, P., Wilson, C., and Nutter, F. W., Jr. 2007. Use of a multispectral radiometer for noninvasive assessments of foliar disease caused by ray blight in pyrethrum. Plant Dis. 91:1397-1406.

37. Pethybridge, S. J., Hay, F. S., and Groom, T. 2003. Seasonal fluctuations in fungi associated with pyrethrum foliage in Tasmania. Aust Plant Pathol. 32:223-230.

38. Pethybridge, S. J., Hay, F. S., Groom, T., and Wilson, C. R. 2008. Improving fungicidebased management of ray blight disease in Tasmanian pyrethrum fields. Plant Dis. 92:887-895

39. Pethybridge, S. J., Hay, F., Jones, S., Wilson, C., and Groom, T. 2006. Seedborne infection 
of pyrethrum by Phoma ligulicola. Plant Dis. 90:891-897.

40. Pethybridge, S. J., Hay, F. S., Wilson, C. R., and Groom, T. 2005. Development of a fungicide-based management strategy for foliar disease caused by Phoma ligulicola in Tasmanian pyrethrum fields. Plant Dis. 89:1114-1120.

41. Pethybridge, S. J., and Wilson, C. R. 1998. Confirmation of ray blight disease of pyrethrum in Australia. Aust. Plant Pathol. 27:4548 .

42. Skinner, W., Bailey, A., Renwick, A., Keon, J., Gurr, S., and Hargreaves, J. 1998. A single amino-acid substitution in the iron sulphur protein subunit of succinate dehydrogenase de- termines resistance to carboxin in Mycosphaerella graminicola. Curr. Genet. 34:393-398.

43. Somers, R. H. 1962. A new asymmetric measure of association for ordinal variables. Am. Sociol. Rev. 6:799-811.

44. Stone, R. C., Hammer, G. L., and Marcussen, T. 1996. Prediction of global rainfall probabilities using phases of the Southern Oscillation Index. Nature 384:252-255.

45. Turechek, W. W., Hartung, J. S., and McCallister, J. 2008. Development and optimization of a real-time detection assay for Xanthomonas fragariae in strawberry crown tissue with receiver operating characteristic curve analysis. Phytopathology 98:359-368.
46. Turechek, W. W., and Wilcox, W. F. 2005 Evaluating predictors of apple scab with receiver operating characteristic curve analysis. Phytopathology 95:679-691.

47. Yuen, J., and Hughes, G. 2002. Bayesian analysis of plant disease prediction. Plant Pathol. 51:407-412.

48. Zito, S. W., Zieg, R. G., and Staba, E. J. 1983. Distribution of pyrethrins in oil glands and leaf tissue of Chrysanthemum cinerariaefolium. J. Med. Plant Res. 47:205-207.

49. Zweig, M. H., and Campbell, G. 1993. Receiver-operating characteristic (ROC) plots: A fundamental evaluation tool in clinical medicine. Clin. Chem. 39:561-577. 